\title{
Morphology and morphometric study of dry scapula, with emphasis on the glenoid fossa and acromion process in Chennai city, South India
}

\author{
Azhagiri $\mathbf{R}^{1}$, Anitha $\mathbf{M}^{2}$, Hemapriya $\mathrm{J}^{3}$, Ganesan Murugaperumal ${ }^{4}$, Sumathi $\mathbf{G}^{5}$ \\ ${ }^{1}$ Associate Professor, Department of Anatomy, ESIC Medical College and PGIMSR, KK Nagar, Chennai, The Tamil \\ Nadu Dr. MGR Medical University, ${ }^{2}$ Assistant Professor, ${ }^{5}$ Professor and Head, Department of Microbiology, Sri \\ Muthukumaran Medical College Hospital and Research Institute, Dr. M.G.R Medical University, Chikkarayapuram, \\ Chennai, Tamil Nadu, ${ }^{3} J R(A C A D) M D$ Lab Medicine, Department of Medicine, ESI Model Hospital and PGIMSR, \\ Indraprastha Guru Gobind University, New Delhi, ${ }^{4}$ Professor and Head, Department of Anatomy, Sree Balaji Medical \\ College and Hospital, Bharath University, Chennai, Tamil Nadu, India
}

A B S T R A C T

Background: The morphology and morphometry of the scapula and its glenoid fossa and acromion process play a significant role in the mechanics of shoulder joint. A variable morphology is found in glenoid fossa that has clinical implications. Aims and Objectives: The aim of the study was to evaluate the morphology and morphometry of dry scapula with emphasis on glenoid fossa and acromion process. Materials and Methods: A cross-sectional study was conducted at the department of anatomy, for a period of 6 months from January 2021 to June 2021. A total of 100 unpaired dry scapula were included in the study. The morphology and dimensions were measured. The dimensions were summarized as mean and standard deviation. Statistical analysis was done Chi-square test and student's t-test based on the variable types. Results: Out of 100 scapulae studied, 48 were right sided and 52 were left sided. The mean of maximum length of the right scapula was $149.58 \pm 10.33 \mathrm{~mm}$ and the left side was $148.63 \pm 10.33 \mathrm{~mm}$. Among the glenoid cavities, 54 were inverted comma shaped, 30 were pear shaped, and 16 were oval shaped. In one right-sided scapula Bony Spur Extends from Base of coracoid process to supra Scapular Notch. Conclusion: Size and shape of the glenoid cavity are directly related to the dislocation of shoulder joint and may affect the results of total shoulder arthroplasty and rotator cuff surgeries. The present study analyzed the morphological types and diameters of the glenoid cavity in adult scapulae to improve the efficacy and minimize the failure rates in shoulder arthroplasty particularly those involving the glenoid component of the shoulder joint.

\section{Access this article online}

Website:

http://nepjol.info/index.php/AJMS DOI: 10.3126/ajms.v13i1.40486

E-ISSN: 2091-0576 P-ISSN: 2467-9100

Copyright (c) 2022 Asian Journal of Medical Sciences

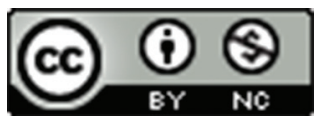

This work is licensed under a Creative Commons Attribution-NonCommercial 4.0 International License.

Key words: Acromion process; Coracoid process; Glenoid cavity; Morphology;

Morphometry; Scapula

\section{INTRODUCTION}

Scapula is a bone forms shoulder girdle and is one of the bones that have variations. It is a flat triangular bone that overlies on the posterolateral aspect of the chest wall over the second to the seventh rib. Its lateral angle becomes truncated and broadened that bears the glenoid cavity which articulates with the head of the humerus in the shoulder joint. The glenoid cavity which is also known as the head of the scapula is connected to the plate like body by an anatomical neck which is most distinct at its dorsal and inferior aspects. When the arm is swing by the side of the body, the glenoid cavity is directed slightly upwards forwards and laterally and when the arm is raised above the head level it is directed almost straight upwards. Scapula possesses three processes and three angles, the acromion, coracoid and the spinous process; the superior, inferior and lateral angles respectively. It also has medial, lateral and 
superior borders and two surfaces which are the anterior or costal surface and the posterior or dorsal surface. ${ }^{1}$

There is a notch present on its antero superior part, that is, on the anterior glenoid rim which gives its different shape. When this glenoid notch is indistinct its shape is piriform or pear or tear drop, when it is distinct it looks like inverted comma shape and when it is absent its oval shape. ${ }^{2}$ Variations in the superior transverse scapular ligament and the suprascapular notch are the most recognized possible predisposing factors for suprascapular notch (SSN) entrapment. ${ }^{3}$

The disproportionate sizes of the head of the humerus and the small, shallow glenoid cavity combined with a lax articular capsule give this joint a wide range of movements but make the joint inherently unstable. ${ }^{2}$

The shoulder joint is the most frequently dislocated joint in the body. Dynamic factors of the rotator cuff muscles and the static factors of the glenohumeral ligaments, the labrum and the joint capsule play a role in gleno-humeral joint stability. Alignment of the humerus and the glenoid articular surfaces is one of the predisposing factors for glenohumeral joint instability, which is one of the predisposing factors for rotator cuff pathology. ${ }^{4}$

Dislocations may also be associated with fracture of the glenoid cavity; for the management of this, prostheses and arthroplasty are required. The knowledge of variations in shape and size of the glenoid fossa are required for better understanding of shoulder joint arthroplasty. These are prerequisites for 2. complete understanding of the mechanics of shoulder joint. This information has clinical application in shoulder arthroplasty, gleno-humeral instability, and rotator cuff tear management. ${ }^{5}$

The variations in the morphology of glenoid fossa are influenced by genetic and environmental factors. ${ }^{6}$ The shoulder is the third most common joint that requires reconstruction following knee and hip. ${ }^{7}$

Therefore, it is mandatory to understand its complex anatomy, which in turn facilitates prompt fabrication of Glenoid implants and screws. Thorough knowledge on the morphometry and morphology of the glenoid fossa is essential in the understanding, investigation and management of demographic diseases pertaining to shoulder such as glenohumeral arthritis, rotator cuff disorders, shoulder dislocations, and fractures. ${ }^{7}$

Therefore, it is mandatory to understand its complex anatomy, which, in turn, facilitates prompt fabrication of Glenoid implants and screws. ${ }^{8}$ Thorough knowledge on the morphometry and morphology of the glenoid fossa is essential in the understanding, investigation and management of demographic diseases pertaining to shoulder such as glenohumeral arthritis, rotator cuff disorders, shoulder dislocations, and fractures. ${ }^{9}$

The knowledge of the shape and dimensions of the glenoid cavity are important in the design and fitting of glenoid component for total shoulder arthroplasty. So deep understanding of variations in normal anatomy of glenoid cavity is essential while dealing with its clinical correlation.

The objective of the study was to obtain anthropometric data of dry human scapulae and the diameters and shapes of the glenoid cavity in the South Indian population and evaluate their clinical significance.

\section{Aims and objectives}

The objective of the study was to evaluate the morphology and morphometry of dry scapula with emphasis on glenoid fossa and acromion process.

\section{MATERIALS AND METHODS}

An observational cross-sectional study was conducted in the department of anatomy, Chennai, during 2021 to June 2021, after taking approval from the Institutional Ethical committee. A morphometric and morphological analysis of 100 adult dry and undamaged human scapulae (48 right side and 52 left sides) was conducted in the South Indian population (Chennai region of Tamil Nadu) to evaluate the parameters of the Glenoid fossa and its relevant clinical significance.

The morphological evaluation was done, and the linear measurements were taken using a Vernier Caliper and recorded in millimeter. The age and sex of the scapulae are unknown. The following parameters were assessed in the study: Various shapes of the Glenoid Fossa were observed (Pear, Oval and Notch type). Acromion and coracoid processes were classified into Type I (flat), II (curved) and III (hooked). ${ }^{10}$ Vertical glenoid diameter was taken along the maximum vertical length of the glenoid fossa between its superior and inferior borders. Horizontal glenoid diameter was taken along the maximum horizontal breadth of the glenoid fossa around its midpoint between the anterior and posterior borders.

The mean, standard deviation, and the P-value correlating the shape and morphometry were calculated separately for the right and the left glenoid cavity. The comparisons in the morphology of the right and left sides were made using statistical analysis.

\section{Inclusion criteria}

- Dry, complete, and both right- and left-sided adult scapulae will be included in the study. 


\section{Exclusion criteria}

- The specimens which are partially broken or have any deformity will be excluded from the study.

- Specimens with osteoarthritic changes, showing any previous trauma sign or skeletal disorders will be excluded from the study.

- Children scapula is excluded from the study.

\section{Statistical analysis}

In the present study, data were analyzed in Microsoft Excel to determine the incidence as percentages. For each morphology and morphometric parameters, maximum; minimum; mean and standard deviation were also calculated. Although it was a descriptive type of analysis, so test of significance was done using Chi-square test and Student's t-test based on the variable types.

\section{RESULTS}

Among the total 100 scapulae studies, 48 were right sided and 52 were left sided (Figure 1). Morphological study was done and measurements were taken. Morphometric analysis was done.

The mean of maximum length of the right scapula was $149.58 \pm 10.33 \mathrm{~mm}$ and the left side was $148.63 \pm 10.33 \mathrm{~mm}$, the difference was not statistically significant. The mean of maximum breadth of the right scapula was $101.40 \pm 5.96 \mathrm{~mm}$ and the left side was 103.65 \pm 7.12 (Table 1).

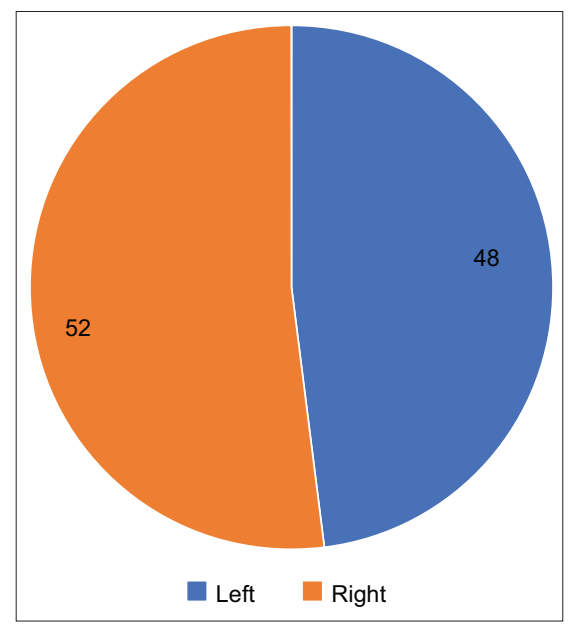

Figure 1: Number of scapula studied $(\mathrm{N}=100)$

\begin{tabular}{|c|c|c|c|c|}
\hline $\begin{array}{l}\text { Whole } \\
\text { scapula }\end{array}$ & $\begin{array}{l}\text { Side of the } \\
\text { scapula }\end{array}$ & Mean & $\begin{array}{c}\text { Std. } \\
\text { Deviation }\end{array}$ & $P$ value \\
\hline \multirow{4}{*}{$\begin{array}{l}\text { Maximum } \\
\text { length } \\
\text { Maximum } \\
\text { breadth }\end{array}$} & Right & 149.58 & 10.334 & \multirow{3}{*}{0.636} \\
\hline & Left & 148.63 & 9.648 & \\
\hline & Right & 101.40 & 5.965 & \\
\hline & Left & 103.65 & 7.121 & 0.090 \\
\hline
\end{tabular}

The mean of maximum length of the right glenoid cavity was $35.17 \pm 2.62 \mathrm{~mm}$ and the left side was $34.73 \pm 2.42 \mathrm{~mm}$, the difference was not statistically significant. The mean of maximum breadth of the right glenoid cavity was $24.12 \pm 1.99 \mathrm{~mm}$ and the left side was $23.73 \pm 1.64 \mathrm{~mm}$, the difference was not statistically significant. The mean of maximum breadth of the upper half of the right glenoid cavity was $17.92 \pm 2.57 \mathrm{~mm}$ and the left was $17.21 \pm 2.56$ (Table 2).

Among the glenoid cavities, 54 were inverted comma shaped, 30 were pear shaped, and 16 were oval shaped.

The mean of maximum length of the right acromion process was $47.08 \pm 5.25 \mathrm{~mm}$ and left side was $43.90 \pm 5.72 \mathrm{~mm}$, the difference was statistically significant $(\mathrm{P}=0.005)$. The mean of maximum breadth of the right acromion process was $23.73 \pm 2.65 \mathrm{~mm}$ and left side was $22.94 \pm 1.95$, the difference was not statistically significant. The acromion-coracoid distance of the right side was $40.60 \pm 4.47 \mathrm{~mm}$ and the left was $42.15 \pm 5.12$. The difference was not statistically different. The mean of acromion-glenoid distance on the right side was $29.58 \pm 4.13$ and on the left side $32.58 \pm 3.83$. The difference in means was statistically significant $(\mathrm{P}=0.000)$ (Table 3).

The inner surface of coracoid process was smooth in 60\% of the scapula and rough in $40 \%$ of the scapula (Figures 2-5).

On comparison of shape parameters between right and left sides, the most common shape of tip of acromion process was intermediate and square. Majority of the

\begin{tabular}{|c|c|c|c|c|}
\hline $\begin{array}{l}\text { Glenoid } \\
\text { cavity }\end{array}$ & $\begin{array}{l}\text { Side of the } \\
\text { scapula }\end{array}$ & Mean & $\begin{array}{c}\text { Std. } \\
\text { Deviation }\end{array}$ & $P$ value \\
\hline \multirow{6}{*}{$\begin{array}{l}\text { Maximum } \\
\text { length } \\
\text { Maximum } \\
\text { breadth } \\
\text { Breadth of } \\
\text { the upper } \\
\text { half }\end{array}$} & Right & 35.17 & 2.625 & \multirow{3}{*}{0.383} \\
\hline & Left & 34.73 & 2.421 & \\
\hline & Right & 24.12 & 1.997 & \\
\hline & Left & 23.73 & 1.647 & \multirow[t]{2}{*}{0.296} \\
\hline & Right & 17.92 & 2.573 & \\
\hline & Left & 17.21 & 2.560 & 0.167 \\
\hline
\end{tabular}

\begin{tabular}{llllc}
\multicolumn{4}{l}{$\begin{array}{l}\text { Table 3: Comparison of measurements of the } \\
\text { right and left acromion process } \\
\text { (N=100) }\end{array}$} \\
\hline $\begin{array}{l}\text { Acromion } \\
\text { process }\end{array}$ & $\begin{array}{l}\text { Side } \\
\text { of the } \\
\text { scapula }\end{array}$ & Mean & $\begin{array}{c}\text { Std. } \\
\text { Deviation }\end{array}$ & $\begin{array}{c}\mathbf{P} \\
\text { value }\end{array}$ \\
\hline Maximum length & Right & 47.08 & 5.254 & 0.005 \\
& Left & 43.90 & 5.721 & \\
Maximum & Right & 23.73 & 2.658 & 0.094 \\
breadth & Left & 22.94 & 1.951 & \\
Acromion- & Right & 40.60 & 4.473 & 0.110 \\
coracoid distance & Left & 42.15 & 5.124 & \\
Acromion-glenoid & Right & 29.58 & 4.132 & 0.000 \\
distance & Left & 32.58 & 3.836 & \\
\hline
\end{tabular}




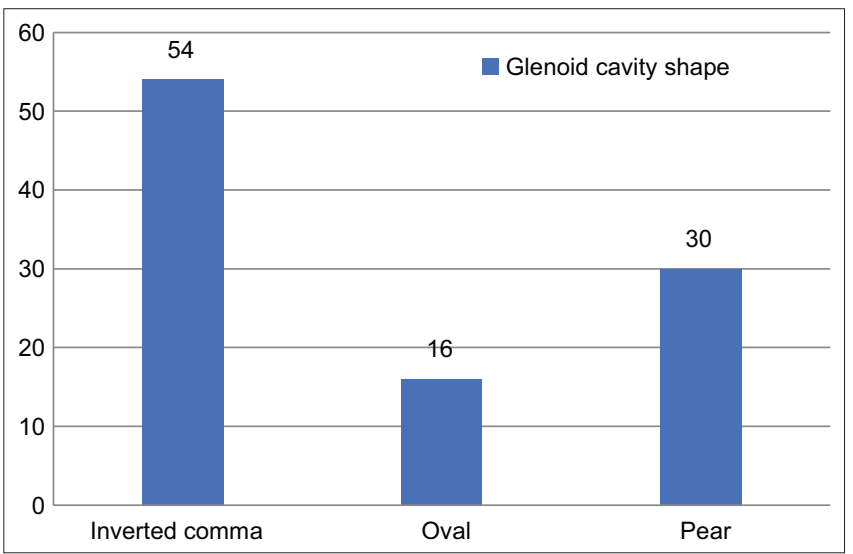

Figure 2: Shape of glenoid cavity $(\mathrm{N}=100)$

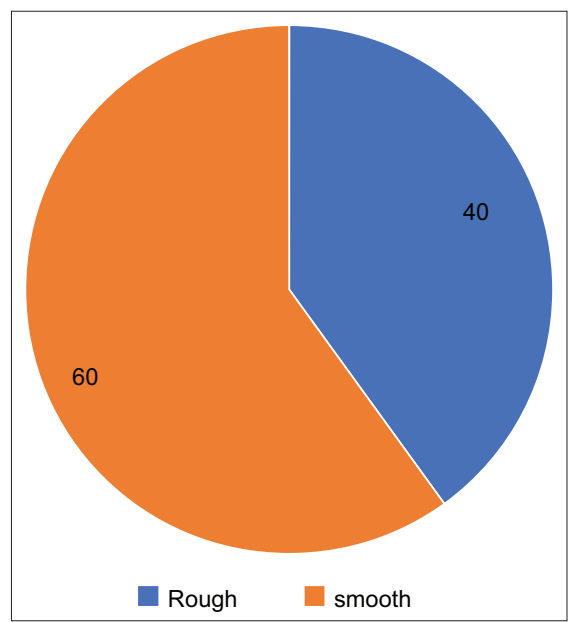

Figure 3: Inner surface of coracoid process $(\mathrm{N}=100)$

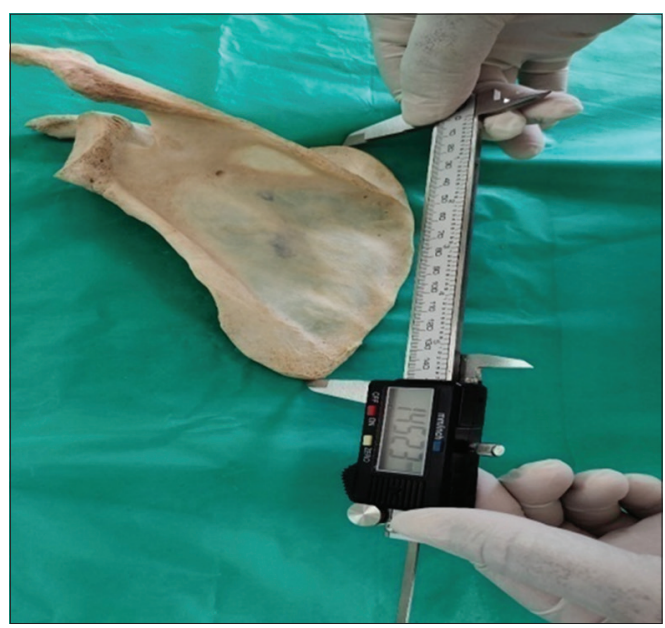

Figure 4: Measuring length of scapulae using Vernier caliper

coracoid process were curved and the under surface was smooth. Majority of the scapulae had glenoid cavity notch. The presence of notch was statistically significant compared between right and left sides $(\mathrm{P}=0.028)$ (Table 4).

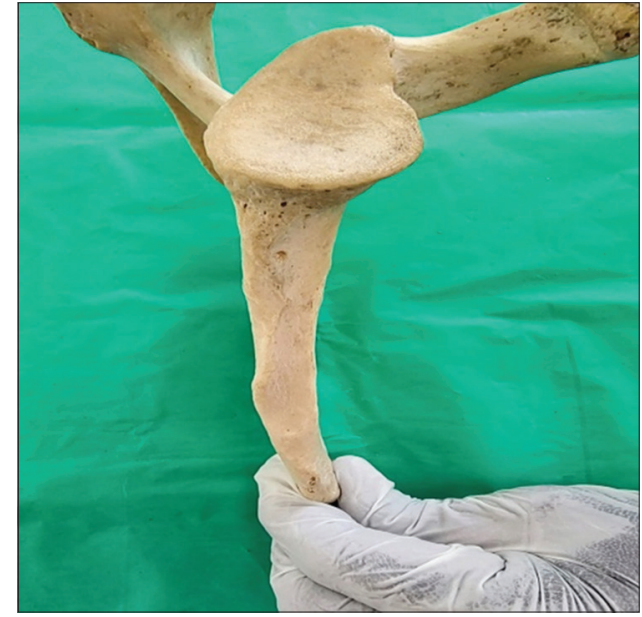

Figure 5: Glenoid cavity inverted comma shaped

\begin{tabular}{|c|c|c|c|}
\hline Shape parameters & $\begin{array}{c}\text { Right } \\
(n=52)\end{array}$ & $\begin{array}{c}\text { Left } \\
(n=48)\end{array}$ & $P$ value \\
\hline \multicolumn{4}{|l|}{$\begin{array}{l}\text { Shape of tip of } \\
\text { acromion process }\end{array}$} \\
\hline Intermediate & 21 & 19 & \\
\hline Square & 19 & 21 & 0.656 \\
\hline Cobra & 12 & 8 & \\
\hline \multicolumn{4}{|l|}{$\begin{array}{l}\text { Curvature of coracoid } \\
\text { process }\end{array}$} \\
\hline Flat & 4 & 6 & 0.804 \\
\hline Slightly curved & 8 & 8 & \\
\hline Curved & 26 & 24 & \\
\hline Hooked & 14 & 10 & \\
\hline \multicolumn{4}{|l|}{$\begin{array}{l}\text { Under surface } \\
\text { (Inferior) of coracoid } \\
\text { process }\end{array}$} \\
\hline Smooth & 32 & 28 & \\
\hline Rough & 20 & 20 & 0.743 \\
\hline \multicolumn{4}{|l|}{$\begin{array}{l}\text { Notch of Glenoid } \\
\text { cavity }\end{array}$} \\
\hline Present & 34 & 35 & \\
\hline Absent & 3 & 8 & 0.028 \\
\hline Slight notch & 15 & 5 & \\
\hline
\end{tabular}

Table 5 compares the morphometric features of glenoid cavity between the right and left sides. Other morphological features included, in one right-sided scapula Bony Spur Extends from Base of coracoid process to supra Scapular Notch (Figures 6 and 7). Margins of acromion facet were prominent in two scapula shallow suprascapular notch that was present in three scapula and more prominent upper lip of crest of spine in one scapula. Margins of glenoid cavity were prominent in five scapulae, deepened cavity seen in one and one lateral margin of glenoid cavity had a tubercle. Numerous foramina in supraspinous fossa were observed in two scapulae and deep supra spinous fossa in one scapula. 


\begin{tabular}{|c|c|c|c|}
\hline \multirow[t]{2}{*}{ Parameter } & \multicolumn{2}{|c|}{$\begin{array}{l}\text { Side of the scapula } \\
\text { (Mean } \pm \text { SD) }\end{array}$} & \multirow[t]{2}{*}{$P$ value } \\
\hline & Right & Left & \\
\hline Inverted comma & $(\mathrm{N}=28)$ & $(\mathrm{N}=26)$ & \\
\hline Maximum length & $35.75 \pm 2.35$ & $35.12 \pm 2.32$ & 0.323 \\
\hline Maximum breadth & $24.29 \pm 1.96$ & $23.96 \pm 1.69$ & 0.519 \\
\hline $\begin{array}{l}\text { Breadth of upper } \\
\text { half }\end{array}$ & $17.86 \pm 2.7$ & $17.31 \pm 2.38$ & 0.433 \\
\hline Pear & $(\mathrm{N}=16)$ & $(N=14)$ & \\
\hline Maximum length & $34.5 \pm 3.43$ & $34.57 \pm 2.28$ & 0.948 \\
\hline Maximum breadth & $23.63 \pm 2.13$ & $23.43 \pm 1.65$ & 0.782 \\
\hline $\begin{array}{l}\text { Breadth of upper } \\
\text { half }\end{array}$ & $18.13 \pm 2.16$ & $17.57 \pm 3.18$ & 0.577 \\
\hline Oval & $(\mathrm{N}=8)$ & $(\mathrm{N}=8)$ & \\
\hline Maximum length & $34.5 \pm 0.93$ & $33.75 \pm 2.96$ & 0.506 \\
\hline Maximum breadth & $24.5 \pm 1.93$ & $23.5 \pm 1.6$ & 0.278 \\
\hline $\begin{array}{l}\text { Breadth of upper } \\
\text { half }\end{array}$ & $17.75 \pm 3.15$ & $16.25 \pm 1.91$ & 0.269 \\
\hline
\end{tabular}

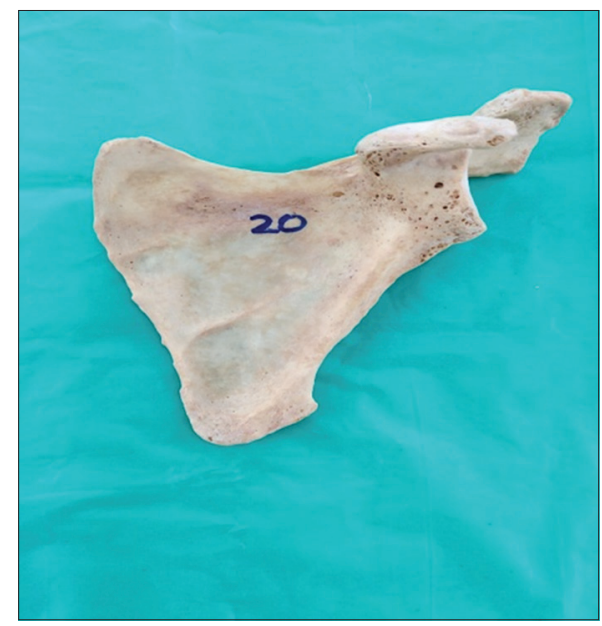

Figure 6: Wide suprascapular notch

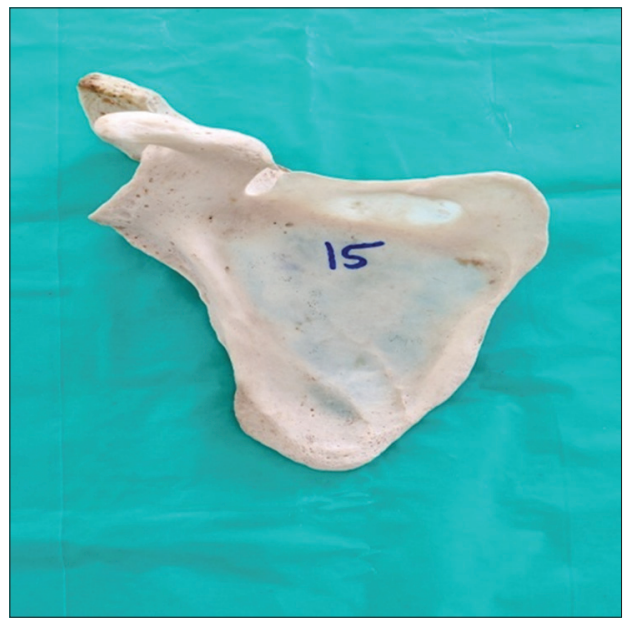

Figure 7: Bony Spur extending from upper end of anterior margin of suprascapular notch and partially converting into suprascapular foramen

\section{DISCUSSION}

In the current study, the sex of the scapulae was not known therefore, male and female bones could not be measured separately. In the present study, the mean maximum length of right acromion was found to be $47.08 \pm 5.25 \mathrm{~mm}$ and the left side was $43.90 \pm 5.72 \mathrm{~mm}$. In a similar study, Mansur et al. ${ }^{11}$ recorded length of acromion to be $46.46 \mathrm{~mm}$ on the right side and $45.57 \mathrm{~mm}$ on the left side in Nepalese population, Whereas Dhindsa and Gupta ${ }^{12}$ reported that the mean maximum length of acromion was found to be on Right $=43.47$ and Left $=42.74)$. Lingamdenne and Marapaka ${ }^{13}$ reported mean length of $43.22 \mathrm{~mm}$ in South Indian population. On the contrary, Gupta et al. ${ }^{14}$ reported a larger left acromial length. Singh et al. ${ }^{15}$ found the acromial length to be longer on the right side which was in accordance with findings of this study.

In the present study, the mean maximum breadth of right acromion was $23.73 \mathrm{~mm}$ and left side was $22.94 \mathrm{~mm}$. Dhindsa and Gupta ${ }^{12}$ reported the mean maximum breadth of right acromion was 24.86 and on left 24.06 . Lingamdenne and Marapaka ${ }^{13}$ reported mean breadth of $24.64 \mathrm{~mm}$ in South Indian population which are similar to this study, while Mansur et al. ${ }^{11}$ recorded breadth of acromion to be $26.63 \mathrm{~mm}$ on the right side and $27.23 \mathrm{~mm}$ on the left side in Nepalese population, which is not similar to this study.

In the present study, the mean acromion-glenoid distance was found to be on the right $40.60 \mathrm{~mm}$ and left $42.15 \mathrm{~mm}$. Contrary to this study, Dhindsa and Gupta ${ }^{12}$ reported that the mean acromion-glenoid distance was found to be on Right $=30.03 \mathrm{~mm}$ and Left $30.27 \mathrm{~mm}$. The acromion-glenoid distance measured by Mansur et al., 16 was $31.83 \mathrm{~mm}$ and $31.97 \mathrm{~mm}$ on the right and left side, respectively, in Nepalese population $24.46 \mathrm{~mm}$ in South Indian population by Lingamdenne and Marapaka. ${ }^{13}$

In the present study, the mean right acromion-coracoid distance was found to be $29.58 \mathrm{~mm}$ and on the left side $32.58 \mathrm{~mm}$. in a similar study Lingamdenne and Marapaka ${ }^{13}$ reported $31.85 \mathrm{~mm}$ in South Indian population. In contrast Dhindsa and Gupta ${ }^{12}$ reported that the mean right acromion-coracoid distance was $36.14 \mathrm{~mm}$ and Left $=37.96 \mathrm{~mm}$. Mansur et al. ${ }^{11}$ recorded it as 39.03 on the right side and $39.39 \mathrm{~mm}$ on the left side in Nepalese population. Singh et al., 16 reported it to be $37.5 \mathrm{~mm}$ in North Indian Population.

The larger distance acromion-glenoid and acromioncoracoid length which were seen on the left side in this 
study, on the contrary, Gupta et al. ${ }^{14}$ observed these parameters to be greater on the left side.

This study found that shape of tip of acromion process was intermediate $(40 \%)$ square $(40 \%)$, and cobra $(20 \%)$. The shape of the coracoid process was found to be curved type coracoids process (50\%), hooked (24), and flat (10\%). The inner surface of coracoid process was smooth in $60 \%$ of the scapula and rough in $40 \%$ of the scapula. Whereas a study done by Moosa et al., ${ }^{16}$ who reported that the shape of tip of acromion process was cobra (23\%), square (31\%), and intermediate (46\%). Types of inferior surface smooth $(74 \%)$ and rough $(26 \%)$. They have found the highest frequency of curved type of acromion process followed by flat and hooked type, respectively.

The study findings show that the most commonly occurring glenoid shape is inverted comma followed by pear and oval shape on both the side. In contrast to this study, many other authors reported Pear shaped glenoid cavity as common shape, Akhtar et al., 9 and Ankushrao and Dombe, ${ }^{17}$ Singh $^{18}$ observed Pear shaped glenoid cavity as a common shape followed by inverted comma and oval shape in Indian scapulae, while Singh et al. ${ }^{19}$ and Sinha et al. ${ }^{20}$ reported pear shape as common shape followed oval shape and inverted comma.

In the present study, the mean of maximum length of the right glenoid cavity was $35.17 \mathrm{~mm}$ and the left side was $34.73 \mathrm{~mm}$, the values of glenoid cavity diameter of the right side were higher then left side. Similarly, Singh et al. ${ }^{19}$ measured that the values of glenoid cavity length were $34.84 \mathrm{~mm}$ on the right side and on the left side were $33.48 \mathrm{~mm}$ followed by other authors Sinha et al. ${ }^{20}$ were almost similar with the present study. While Akhtar et al. ${ }^{8}$ and Mahto and $\mathrm{Omar}^{21}$ reported higher values $36.03 \mathrm{~mm}$, $37.03 \mathrm{~mm}$, and $36.2 \mathrm{~mm}$, respectively, in comparison to the present study. Values of glenoid cavity diameter of the left side were reported higher then right side in the study by Mamatha et al..$^{22}$ and Sinha et al. ${ }^{20}$

In the present study, the mean of maximum length of the right scapula was $149.58 \pm 10.33 \mathrm{~mm}$ and the left side was $148.63 \pm 10.33 \mathrm{~mm}$, which was close to the findings observed in Tamil Nadu population by Rajeswari and Ramalingam ${ }^{23}$ showed that the mean length of scapula was $141.34 \mathrm{~mm}$ with a SD of $8.5 \mathrm{~mm}$. However, studies in European, Turkish and Egyptian population had slightly different morphometry. El-Din andAli, ${ }^{7}$ Coskun et al., ${ }^{24}$ and Flower and Garson, ${ }^{25}$ the present study findings were similar to studies done by various Indian studies morphometry such as breadth scapular morphometry $99.32 \mathrm{~mm}$ ) and Krishnaiah ${ }^{26}$ showed (length scapular morphometry $143.25 \mathrm{~mm}$ and breadth scapular morphometry $105.59 \mathrm{~mm}$ ).

In the result of this study, one right-sided scapula bony spur extended from base of coracoid process to supra scapular notch (SSN). Shoulder injuries may be a main cause of the formation of bony spurs. Similarly, Polguj et al. ${ }^{27}$ and Zhang et al. ${ }^{28}$ reported the presence of a bony findings in the right side. However, in contrast, Toneva and Nikolova ${ }^{29}$ reported in the left scapula, whereas Agrawal et al. ${ }^{30}$ were not observed this type of morphology of the SSN.

The significant finding of this study suggests that both right and left bone parameters should be measured. The morphometry of GC helps in the analysis of frequent dislocation of the glenohumeral joint and complications of rotator cuff disease. The procedures for total shoulder arthroplasty also suffer from complexities when they encounter anatomical variants such as bony defects of the anterior and/or posterior margins of GC. These defects lead to incomplete restorations of this joint. ${ }^{24}$

There can be differences in nationality and race. Accordingly, correct knowledge of the variations in glenoid morphology and morphometry is critical for a better understanding of clinical applications and shoulder pathology for the design and fitting of glenoid components for shoulder arthroplasty. The above details on glenoid cavity structure and proportions support orthopedics and prosthetists.

\section{Limitations of the study}

The study was under taken only a period of six months.

\section{CONCLUSION}

A definite knowledge regarding the normal morphology is needed. The significant finding of this study suggests the both right and left bone parameters should be measured. Study of morphology and measurement of scapulae plays an important role in clinical significance for proper maintenance of posture and functioning of shoulder. The clinicians need to be familiar with the appearance of suprascapular notch on dry bones, so that he/she can interpret its morphology and morphometry. This will help them to correlate the association between various morphological measurements of the suprascapular notch which will assist them to decide the modality of the treatment.

\section{ACKNOWLEDGMENT}

We would like to thank the management for their immense support provided to complete this project successfully. 


\section{REFERENCES}

1. Johnson D. Pectoral girdle, shoulder region and axilla. In: Standring S, Borley NR, Collins P, Crossman AR, Gatzoulis MA, Healy JC, editors. Gray's Anatomy: The Anatomical Basis of Clinical Practice. $40^{\text {th }}$ ed.London: Churchill Livingstone; 2013. p. 791-822.

http://dx.doi.org/10.18203/2320-6012.ijrms2016194

2. Churchill RS, Brems JJ and Kotschi H. Glenoid size, inclination, and version: An anatomic study. J Shoulder Elb Surg. 2001;10(4):327-332.

http://dx.doi.org/10.1067/mse.2001.115269

3. Bayramoglu A, Demiryurek D, Tuccar E, Erbil M, Aldur MM, Tetik $\mathrm{O}$, et al. Variations in anatomy at the suprascapular notch possibly causing suprascapular nerve entrapment: An anatomical study. Knee Surg Sports Traumatol Arthrosc. 2003;11(6):393-438. http://dx.doi.org/10.1007/s00167-003-0378-3

4. Hassanein $\mathrm{GH}$. Morphometry of glenoid fossa in adult Egyptian Scapulae Int J Anat Res 2015;3(2):1138-1142. http://dx.doi.org/10.16965/ijar.2015.179

5. Dhindsa GS and Singh Z. A study of morphology of glenoid cavity. J Evol Med Dent Sci. 2014;3(25):7036-7043.

http://dx.doi.org/10.14260/jemds/2014/2856

6. Wilk KE, Arrigo CA and Andrews JR. Current concepts: The stabilizing structures of the glenohumeral joint. J Orthop Sports Phys Ther. 1997;25(6):364-379.

http://doi.org/10.2519/jospt.1997.25.6.364

7. El-Din WA and Ali MH. A morphometric study of the patterns and variations of the acromion and glenoid cavity of the scapulae in Egyptian population. J Clin Diagn Res. 2015;9(8):AC08-11. http://doi.org/10.7860/JCDR/2015/14362.6386

8. Akhtar M, Kumar B, Fatima $\mathrm{N}$ and Kumar V. Morphometric analysis of glenoid cavity of dry scapulae and its role in shoulder prosthesis. Int J Res Med Sci. 2016:2770-2776.

http://doi.org/10.9790/0853-1909090105

9. Miles AE. The glenoid notch and the shape of the glenoid cavity of the scapula. J Anat. 1997;191(3):475-475.

http://doi.org/10.1046/j.1469-7580.1997.19130475.x

10. Bigliani LU, Morrison DS and April EW. The morphology of acromion and its relationship to rotator cuff tears. Orthop. Trans 1986;10():228. https://doi.org/10.1016/S0278-5919(20)30586-X

11. Mansur DI, Khanal K, Haque MK and Sharma K. Morphometry of acromion process of human scapulae and its clinical importance amongst Nepalese population. Kathmandu Univ Med J. 2012;38(2):33-36.

https://doi.org/10.3126/kumj.v10i2.7340

12. Dhindsa GS and Gupta V. Morphometric study of the acromion process and its clinical relevance. Asian J Med Res. 2019;8(3):AT2.

https://doi.org/10.21276/ajmr.2019.8.3.AT2

13. Lingamdenne PE and Marapaka P. Measurement and analysis of anthropometric measurements of the human scapula in Telangana Region, India. Int J Anat Res. 2016;4(3):2677-2683. http://doi.org/10.16965/IJAR.2016.302

14. Gupta C, Priya A, Kalthur SG and D'Souza AS. A morphometric study of acromion process of scapula and its clinical significance. CHRISMED J Health Res. 2014;1(3):164-169.

http://doi.org/10.4103/2348-3334.138885

15. Singh J, Pahuja K and Aggarwal R. Morphometric parameters of the acromion process in adult human scapulae. Indian J Basic Appl Med Res. 2013;8(2):1165-1170.

http://doi.org/10.7860/JCDR/2017/21060.9312
16. Moosa SS, Riyaz ZH and Siddiqui AA. A morphometric study of the patterns and variations of the acromion of scaptulae in Maharastrian population. Indian J Anat. 2017;6(4):86-91.

http://dx.doi.org/10.21088/ija.2320.0022.6417.24

17. Ankushrao SD and Dombe DD. Morphological and morphometrical study of scapulae in Western Indian population. Ind J Clin Anat Physiol. 2017;4(3):298-303.

http://doi.org/10.7860/IJARS/2019/41437:2487

18. Singh R. Surgical anatomy of the glenoid cavity and its use in shoulder arthroplasty among the north Indian population. Cureus. 2020;12(12):e11940.

http://doi.org/10.7759/cureus. 11940

19. Singh A, Singh A, Agarwal P and Gupta R. A morphological and morphometric study of glenoid fossa of scapula and its implication in shoulder arthroplasty. Int J Anat Radiol Surg. 2019;8(3):AO06-AO09.

http://doi.org/10.7860/IJARS/2019/41437:2487

20. Sinha P, Bhutia KL, Tamang B and Sarda RK. Morphometric study of glenoid cavity of dry human scapula. Int J Med Res Prof. 2016;2(3):86-90.

http://doi.org/10.14260/jemds/2020/508

21. Mahto AK and Omar S. Dimensions of glenoid fossa of scapula: Implications in the Biomechanics of an implant design. Int J Sci Stud. 2015;3(4):146-148.

http://doi.org/10.7860/IJARS/2019/41437:2487

22. Mamatha T, Pai SR, Murlimanju BV, Kalthur SG, Pai MM and Kumar B. Morphometry of glenoid cavity. Online J Health Allied Sci. 2011;10(3):1-4. http://dx.doi.org/10.18203/2320-6

23. Rajeswari K and Ramalingam P. Study of morphometric analysis of scapula and scapular indices in Tamil Nadu population. IOSR J Dent Med Sci. 2018;17(4):37-42.

http://doi.org/10.9790/0853-1704103742

24. Coskun N, Karaali K, Cevikol C, Demirel BM and Sindel M. Anatomical basics and variations of the scapula in Turkish adults. Saudi Med J. 2006;27(9):1320-1325.

http://doi.org/10.7759/cureus.11940

25. Flower WH and Garson JG. The scapular index as a race character in man. J Anat Physiol. 1879;14(Pt 1):13-17. http://doi.org/10.14260/jemds/2020/508

26. Krishnaiah DM, Nagaraj S, Kumar PM and Sherke AR. Study of scapular measurements and scapular indices of Andhrapradesh Region. IOSR J Dent Med Sci. 2014;13(6):117-120. http://doi.org/10.9790/0853-1361117120

27. Polguj M, Jędrzejewski K, Podgórski M, Majos A and Topol M. A proposal for classificationof the superior transverse scapular ligament: Variable morphology and its potential influence onsuprascapular nerve entrapment. J Shoulder Elbow Surg. 2013;22(9):1265-1273.

http://doi.org/10.1155/2017/4659761

28. Zhang L, Xu J, Fu S, Qin B, Liu Y, Yang Y, Wang M, et al. Bony spurs on the coracoid process in a Chinese population. Anatomy of the coracoid bony spurs. Med Sci Monit. 2019;25:2527-2534. http://doi.org/10.12659/MSM.913658

29. Toneva $D$ and Nikolova S. Coexistence of a suprascapular notch and a bony canal: A rare anatomical variation. Acta Morphol Anthropol. 2015;22:127-134. http://doi.org/10.1007/s12565-012-0165-7

30. Agrawal D, Singh B and Agrawal G. Human scapulae: Supra scapular notch, morphometry and variations. Indian J Clin Anat Physiol. 2014;1:1-7. 


\section{Authors' Contributions:}

AR- Concept and design of the study, data collection, prepared first draft of manuscript, and interpreted the results; AM- Tabulation of results, statistical analysis;

HJ- Data analysis, literature review; GM- Revision of the manuscript; SG- Manuscript drafting

Work attributed to:

ESIC Medical College and PGIMSR, KK Nagar, Chennai, Tamil Nadu, India

\section{ORCID ID:}

Dr. Azhagiri R - (10) https://orcid.org/0000-0002-4497-0004

Dr. Anitha Malar- (1) https://orcid.org/0000-0003-1440-7218

Dr. Hemapriya J- (i) https://orcid.org/0000-0001-9847-6856

Dr. Ganesan Murugaperumal- (1) https://orcid.org/0000-0001-7323-5503

Dr. Sumathi G - (1) https://orcid.org/0000-0002-1731-4394 